\title{
Channel-forming leucotoxins from Staphylococcus aureus cause severe inflammatory reactions in a rabbit eye model
}

\author{
J. A. SIQUEIRA, C. SPEEG-SCHATZ, ${ }^{*}$ F. I. S. FREITAS, $\dagger$ J. SAHEL, ${ }^{*}$ H. MONTEIL $\dagger$ and \\ G. PRÉVOST†
}

Instituto Hilton Rocha, Ave Anel DaSerra 1335, Mangabeiras, Caixa postal 700, Belo Horizonte 302010-090, Brazil, "Clinique Ophthalmologique des Hôpitaux Universitaires de Strasbourg, 1 Place de l'Hôpital, F-67000 Strasbourg and +Institut de Bactériologie de la Faculté de Médecine, Université Louis Pasteur, 3 rue de Koeberlé, F-67000 Strasbourg, France

\begin{abstract}
Panton-Valentine leucocidin arises from the combination of one $\mathrm{S}$ component (LukS-PV) with one $\mathbf{F}$ component (LukF-PV), whereas $\gamma$-haemolysin comprises two $\mathbf{S}$ components (HIgA and $\mathrm{HIgC}$ ) with one $\mathrm{F}$ component HIgB. The intravitreal injection of rabbit eye with the six combinations $(\mathrm{S}+\mathrm{F})$ of channel-forming leucotoxins produced by Staphylococcus aureus ATCC 49775 induced acute inflammatory reactions depending on time and doses of toxins. These reactions involved posterior chamber as well as anterior chamber and conjunctiva, eyelids and annexes. Histological examination confirmed the involvement of eye tissues and the disruption of the retinal barrier. The lesions began only $4 \mathrm{~h}$ after injections and persisted for at least 5 days. Clinical and biological effects of each leucotoxin were modulated by the speed of onset and intensity of inflammation and necrosis, leading to a functional classification according to the severity of the lesions (HIgA + LukF-PV $>$ HlgA + HlgB $\geqslant$ LukS-PV + HlgB $\geqslant$ LukSPV + LukF-PV $>$ HlgC + HIgB $\geqslant$ HlgC + LukF-PV). Moreover, N-acetyl $\beta$-D glucosaminidase assays on crude extracts of vitreous revealed granules and granule secretions from polymorphonuclear cells with levels according the above classification. These results show that channel-forming leucotoxins have a very significant inflammatory activity. As most $S$. aureus strains produce two or even six leucotoxins depending on the production of Panton-Valentine leucocidin, these compounds could be considered to be virulence factors.
\end{abstract}

\section{Introduction}

Staphylococcal channel-forming leucotoxins are exotoxins consisting of two non-associated, but synergic class $\mathrm{S}$ and class $\mathrm{F}$ proteins $[1,2]$. These toxins constitute a recently described protein family $[3,4]$, and two of them are produced from two different chromosomal loci of Staphylococcus aureus ATCC 49775. The first, encoding the Panton-Valentine leucocidin [3-6], consists of two co-transcribed genes, where the upstream one encodes a class $\mathrm{S}$ component (LukS-PV) and the downstream one a class $\mathrm{F}$ component (LukF-PV). The second locus encodes $\gamma$ haemolysin, of which four molecular variants have been reported $[3,4,7-12]$. There is $>95 \%$ sequence

Received 24 April 1996; revised version accepted 24 Oct. 1996.

Corresponding author: Dr G. Prévost. identity within the homologous proteins of these four variants. This second locus in fact consists of three genes, the first two encoding class $\mathrm{S}$ proteins (HlgA and $\mathrm{HlgC}$ ), and the third encoding a class $\mathrm{F}$ protein $(\mathrm{H} \operatorname{lgB})$. The genes $h l g \mathrm{C}$ and $h \lg \mathrm{B}$ are co-transcribed and $h l g \mathrm{~A}$ constitutes an upstream open reading frame. As the four molecular variants of this second locus are constituted by two class $\mathrm{S}$ components (HlgA and $\mathrm{HlgC}$ ), and by a single class $\mathrm{F}$ protein component (HlgB), each toxin of the $\gamma$-haemolysin group is, in fact, constituted of two different leucotoxins: $\mathrm{HlgA}+$ $\mathrm{HlgB}$ and $\mathrm{HlgC}+\mathrm{HlgB}$.

These toxins are known as membrane-directed toxins [13-15]; their targets are human host defence cells such as polymorphonuclear cells, monocytes and macrophages $[2,16]$. It has been demonstrated by different methods that the first component that binds to target cells $[14,15]$ belongs to the structurally related class $\mathrm{S}$ proteins, thus allowing further inter- 
action in an as yet undetermined stoichiometry, of a structurally related class $\mathrm{F}$ protein that is required to induce biological activity. Panton-Valentine leucocidin (PVL) has only leucotoxic properties [16], whereas $\gamma$ haemolysin ( $\mathrm{Hlg} \mathrm{A}+\mathrm{HlgB}$ and $\mathrm{HlgC}+\mathrm{HlgB})$ has leucotoxic and also haemolytic properties. PVLproducing $S$. aureus strains are mostly associated with furuncles and vice versa $[17,18]$, but they represent only $2 \%$ of clinical hospital strains, whereas strains producing only $\gamma$-haemolysin represent $97 \%$ of clinical isolates [18]. In fact, PVL-producing strains produce not only PVL, but also $\gamma$-haemolysin, simultaneously [3], leading to the secretion of three class $\mathrm{S}$ components and two class $\mathrm{F}$ components. Moreover, the interchangeability inside the class $\mathrm{S}$ or class $\mathrm{F}$ components gives rise to the possibility of six combinations.

PVL (LukS-PV + LukF-PV) is one of the six possible combinations. The purified toxin has been shown to induce severe inflammatory lesions when injected intradermally into rabbit skin $[19,20]$, leading to capillary dilatation, chemotaxis, infiltration of polymorphonuclear leucocytes (PMNL), PMNL-cell caryorrhexis and finally tissue necrosis. In the same way, PVL was shown to induce the secretion of chemotaxis mediators from 'PMNLs, such as leucotriene $\mathrm{B}_{4}$ [21] and interleukin (IL)-8 [22]. At the opposite end of the scale, the two pairs constituting $\gamma$-like haemolysin did not elicit tissue necrosis of rabbit skin, although they induced inflammatory lesions and mediators $[23,24]$.

The study of the biological activity of toxins on animal models is a prerequisite before injection of bacteria producing selected leucotoxins. However, the rabbit skin model is limited because the intradermal injection of $S$. aureus ATCC 49775 that produced PVL in vitro did not generate skin necrosis in vivo. It was not known whether this lack of necrosis was due to the inhibition of bacterial growth or to the inhibition of toxin production in rabbit skin. This led to the choice of another animal model with specific characteristics. First, the chosen model for bacterial infections should have a parallel in human pathology. Second, the staphylococci should have been demonstrated to grow and induce inflammatory lesions in this model. Third, the sampling procedure should be easy to do in order to obtain rapidly liquid samples in which inflammatory mediators could be quantified. Fourth, the injected toxins or bacteria should have a slow clearance, thus maximising biological effects and allowing an objective determination of bacterial growth. Fifth, some of the animal cells had to be sensitive to the action of the toxin in vitro. The model of the vitreous of the rabbit eye was chosen because it fulfilled most of the above criteria. Furthermore, after stimulation of the immune response, inflammatory cells which are normally scant inside the vitreous may accumulate in this area through the haemo-retinal barrier. The ability of staphylococci to grow and to induce inflammatory lesions in the vitreous of rabbits has been reported previously $[25,26]$. This model has also been used for studies of the biological activity of pneumolysin [27]. Before further experiments to establish their role in bacterial pathogenicity, it was necessary to determine the impact of each of these purified pairs of leucotoxins in the rabbit eye vitreous.

\section{Materials and methods}

\section{Bacterial toxins}

Protein components of channel-forming leucotoxins, i.e., LukS-PV, LukF-PV, HlgA, HlgC and HlgB were purified from $S$. aureus ATCC 49775 as described previously [3] and were diluted in sterile apyrogenic physiological medium. Each equimolar combination of proteins constituting leucotoxins was injected at doses of 3, 30, 300 or $3000 \mathrm{ng}$ of each component per $50 \mu \mathrm{l}$ of physiological solution. The combinations injected were each of the six possible pairs of class $\mathrm{S}$ and class $\mathrm{F}$ components. Controls were apyrogenic physiological solution and each protein component injected alone.

\section{Rabbits and injections}

The experimental procedures were in accordance with the ARVO resolution on the use of animals in research. Permission (no. 04683) to experiment on animals was given by the French Ministry of Forests and Agriculture. Ten-week-old New Zealand White rabbits weighing $2.0-2.5 \mathrm{~kg}$ were given injections into the right eye after anaesthesia by intramuscular injection of $300 \mu \mathrm{l}$ of reconstituted Zoletil $囚$-100 (Reading Laboratories, London). Atropine sulphate (Alcon Laboratories, Courbevoie, France) $0.3 \%(\mathrm{w} / \mathrm{v})$ was then instilled into the rabbit eyes and 2 min later oxybuprocain hydrochloride (Chauvin Laboratories, Montpellier, France). Injections of $50 \mu \mathrm{l}$ of diluted leucotoxin were made through the pars plana into the vitreous with a 25 -gauge needle, taking care to avoid touching the crystalline lens and injecting within the retina. This injection also required the slow removal of the needle, in order to avoid backward flow of toxin under the conjunctiva.

\section{Clinical investigations}

Eyes were observed clinically $4 \mathrm{~h}, 24 \mathrm{~h}$ and $48 \mathrm{~h}$ after injection. Clinical modifications of the posterior chamber were assessed by direct ophthalmoscopy (Heine) according to the criteria of Nussenblatt et al. [28]. Briefly, five increasing levels of severity of damage were defined: 0 , normal eye without vitreous haze; 1 , vitreous haze allowing observation of the optic nerve and retinal vessels; 2 , vitreous haze still allowing observation of vessels and optic nerve, but with difficulty; 3 , vitreous haze allowing observation of 
the optic nerve only, its boundaries being blurred; 4 , vitreous haze preventing observation of the optic nerve.

The clinical investigation of the anterior chamber and its annexes also resulted in the distinction of five increasing levels of severity of the lesions: 0 , normal eye with no physical damage; 1 , a slight conjunctival hyperaemia located around the site of injection; 2, the presence of conjunctival hyperaemia involving at least half of the surface and associated with scant discharge, but without haze in the anterior chamber. There was no clinical change in the eyelids, nor in the cornea, nor in the anterior chamber, at inflammatory levels 1 and 2. If clinical damage increased (stages 3 and 4), the clinical description was completed with details of the eyelids: blepharitis and oedema. The importance of secretions, partial or total damage to the cornea and the corneal state (haze, ulceration) were also noted, as well as the state of the anterior chamber (hypopyon, hyphema, fibrin). Level 3 showed moderate secretions, slight blepharitis, total conjunctival hyperaemia involving all the eyeball, perikeratic injection, chemosis, and a slight haze of the anterior chamber, still allowing observation of the iris. At stage 4 , again, total conjunctival hyperaemia, blepharitis and oedema, chemosis and secretions were found. The secretions were more obvious and these features were associated with a significant haze of the anterior chamber which prevented observation of the iris. Hypopyon and phtisis occurred only occasionally at this stage. Clinical observations were made for all rabbits used either for histological examinations or glucosaminidase assays.

\section{Histopathological observations}

After clinical examination, anaesthetised rabbits were killed immediately by intracardiac injection of pentobarbital (Sanofi, Libourne, France) $1.5 \mathrm{ml} / \mathrm{kg}$, before immediate enucleation of the eyeball. Eyes were fixed in formaldehyde $10 \%(\mathrm{v} / \mathrm{v})$ for at least $48 \mathrm{~h}$, embedded in paraffin, and then cut in $5-\mu \mathrm{m}$ thick sections. Before microscopic observation $(\times 400)$, sections were stained with haematoxylin and eosin.

Microscopic observation included the cornea, anterior chamber, iris, vitreous space, retina and sclera. The structure of tissues, presence of cell infiltrate and local necrosis of tissues were recorded. According to the histological modifications observed, five histological levels were defined: 0 , corresponded to a normal eye without blood cell in the vitreous and without damage to the tissues; 1 , the presence of a few erythrocytes in the vitreous without leucocytes and without tissue necrosis; 2 , characterised by an inflammatory infiltrate in the vitreous of up to 300 inflammatory cells per microscopic field $(\times 400)$, without necrosis; congestion of the iris and of the choroid were also noticed. At level 3 haemorrhage in the vitreous was still moderate but there were between 300 and 800 inflammatory cells per microscopic field. There was also partial necrosis of the retina and severe congestion of the iris and the choroid. Level 4 showed severe haemorrhage and congestion of the iris and the choroid. Additionally, inflammation of the posterior chamber with $>800$ cells/field occurred, and also involved the anterior chamber, iris, ciliary body and choroid. Necrosis extended to the whole retina and was often associated with partial necrosis of the corneal endothelium, iris, ciliary body and choroid. Independent histological examinations were made as two independent series.

The two clinical scores and the histological one recorded for each inflammatory reaction were summed to give an 'inflammatory score' (IS) for each eye. Thus, the IS reflects the sensitivity of the rabbit eye 4 , 24 or $48 \mathrm{~h}$ after injection of a given leucotoxin at a given dose into the vitreous.

\section{$N$-acetyl $\beta$-D glucosaminidase assays}

Vitreous samples $(300 \mu 1)$ containing inflammatory cells were harvested from killed rabbits 24,48 and $72 \mathrm{~h}$ after injections and were diluted in Triton X-100 $0.1 \%$. After centrifugation for $5 \mathrm{~min}$ at $0^{\circ} \mathrm{C}$ and $10000 \mathrm{~g}$ cell debris was discarded. Lysate supernates were diluted five-fold and 10-fold in PBS (Dulbecco). Enzymic reactions were initiated [14] by mixing $50 \mu \mathrm{l}$ of diluted lysate and $50 \mu \mathrm{l}$ of $1 \mathrm{mM} p$-nitrophenyl-Nacetyl- $\beta$-D-glucosaminide solubilised in $0.2 \mathrm{M}$ sodium citrate, $\mathrm{pH} 4.5$, at room temperature. Reactions were stopped after $30 \mathrm{~min}$ and $1 \mathrm{~h}$ by the addition of $100 \mu \mathrm{l}$ of $1 \mathrm{M}$ Tris- $\mathrm{HCl}, \mathrm{pH}$ 9.0. Optical density was recorded at $405 \mathrm{~nm}$. Assays were performed twice on given samples as four independent series from different rabbits.

Clinical and histological observations and glucosaminidase assays were performed in double-blinded fashion.

\section{Statistical procedures}

Statistical analysis was performed with the Statistical Analysis System program (SAS Institute, Cary, NC, USA). The non-parametric tests of Kruskall-Wallis and Wilcoxon-Mann-Whitney were used for comparison of the data obtained from clinical and histological observations, and the $\chi^{2}$ test for values obtained from $\mathrm{N}$-acetyl $\beta$-D-glucosaminidase assays; $\mathrm{p}<0.05$ results were considered statistically significant.

\section{Results}

\section{Time and dose-dependent reactions}

During these experiments, apyrogenic physiological solution and doses of $3000 \mathrm{ng}$ of each protein alone were injected into rabbit eyes as controls. Each control 
induced reaction level 1 in posterior and anterior chambers as well as reaction level 1 for histological observation, 4,24 or $48 \mathrm{~h}$ after injection. The reaction obtained with two individual proteins was significantly different from that obtained with the corresponding tested pair $(p<0.001)$, demonstrating the synergy between leucotoxin components. This reaction was assumed to be due to the injection only. No noticeable clinical or histological differences were observed following identical injections in different rabbits.

As listed in Table 1, with doses of 3 or $30 \mathrm{ng}$ of leucotoxins ( $\mathrm{S}$ and $\mathrm{F}$ combinations), the inflammatory reactions were not different from those of the negative controls, at 4, 24 or $48 \mathrm{~h}$, except for a dose of $30 \mathrm{ng}$ each of $\mathrm{HlgA}+\mathrm{LukF}-\mathrm{PV}$, which was enough to generate a haze in the posterior chamber within $48 \mathrm{~h}$, with the optic nerve being barely visible (stage 3). The latter difference was statistically significant $(p<0001)$ from observations with the rest of the pairs tested. For all the pairs of $\mathrm{S}$ and $\mathrm{F}$ components, equimolar doses of $300 \mathrm{ng}$ and $3000 \mathrm{ng}$ induced significant and different time-dependent reactions. These reactions began to be noticeable only $4 \mathrm{~h}$ after injection, except for the two pairs containing $300 \mathrm{ng}$ of the component $\mathrm{HlgC}$, when the reaction was delayed. The latter feature was confirmed in each of the clinical and histological observations, and was hence evidenced by the IS. As measured at different times following injections, the effects of toxins were progressive up to $48 \mathrm{~h}$, except for some pairs such as $\mathrm{H} \lg \mathrm{A}+\mathrm{LukF}-\mathrm{PV}$ and $\mathrm{H} \lg \mathrm{A}+\mathrm{HlgB}$, where the maximal effects $(I S=12)$ were reached $24 \mathrm{~h}$ after injection of equimolar doses of $3000 \mathrm{ng}$ of the components $(\mathrm{p}<0.01)$. This maximal damage (IS $=12)$ was reached within $48 \mathrm{~h}$ or less with at least $3000 \mathrm{ng}$ for four of the six combinations of $\mathrm{S}$ and $\mathrm{F}$ components, being significantly different from the damage generated by the two pairs including $\mathrm{HlgC}$ within $48 \mathrm{~h}$ $(\mathrm{p}<0.005)$.

Observation at 15 days after injection with 300 and $3000 \mathrm{ng}$ each of LukS-PV + LukF-PV (PVL) revealed that the clinical lesions were stable only between $48 \mathrm{~h}$ and 5 days. The reactions decreased slowly in the anterior chamber during the following days. For example, after injection of equimolar doses of $300 \mathrm{ng}$ and $3000 \mathrm{ng}$ of PVL, the inflammatory lesions in the anterior chamber changed from stages 3 and 4 to stages 2 and 3, respectively, between days 5 and 15 .

With the injection of an equimolar dose of $3000 \mathrm{ng}$ of PVL, the reaction score of the posterior chamber (stage 4) was stable from 2 to 15 days after injection, whereas it decreased (from stage 4 to stage 3) following the injection of an equimolar dose of $300 \mathrm{ng}$ of PVL during the same period. For these rabbits, histological examination at day 15 after injection revealed that healing of all the necrotic tissues had begun.
Biological activity of channel-forming leucotoxins in the rabbit eye

An equimolar dose of $300 \mathrm{ng}$ of the channel-forming leucotoxins appeared to be that which induced the most variable and progressive intensities of clinical reactions, according to the time of observation. It appeared that the pairs that included HlgA were the most potent, those with $\mathrm{HlgC}$ were responsible for less acute inflammatory reactions and those with LukS-PV had an intermediate activity. In addition, the combination $\mathrm{H} \lg \mathrm{A}+\mathrm{HlgB}+\mathrm{HlgC}$, which would occur naturally, if the three components constituting $\gamma$-haemolysin were produced by most $S$. aureus strains in equimolar concentrations, was studied. Time and dose-dependent responses were also noted for this combination. The maximal damage, represented by total retinal necrosis, was observed $48 \mathrm{~h}$ after the injection of $3000 \mathrm{ng}$ of each of the three components ( IS $_{3000 n g} 4,24,48 \mathrm{~h}=7$, 11,12 , respectively). The severity of the lesions and the rapidity of their formation were intermediate between those induced by the pairs $\mathrm{HlgA}+\mathrm{HlgB}$ and $\mathrm{HlgC}+\mathrm{HlgB}$, probably because $\mathrm{HlgB}$ had to be distributed among the two class $\mathrm{S}$ components, $\mathrm{HlgC}$ and $\mathrm{HlgA}$, in order to form respective channels. However, the two-fold increase of dose of HlgB did not induce appreciable variation $(p>0.05)$ of the inflammatory response if compared with the above.

In such a way, a classification of the leucotoxins was assessed. The combination HlgA + LukF-PV was the most efficient pair. Eyes given an equimolar dose of $3000 \mathrm{ng}$ of this combination demonstrated the highest inflammatory score only $24 \mathrm{~h}$ after injection, as did $\mathrm{HlgA}+\mathrm{H} \operatorname{lgB}$. Furthermore, only this pair when injected at an equimolar dose of $30 \mathrm{ng}$ was responsible for a significant inflammatory reaction after $48 \mathrm{~h}$. In addition, this was the only pair to induce corneal ulceration and cataract associated with hypopyon and necrosis of the ciliary body, the choriocapillar cells and of the whole retina.

The potential of inflammation of three other combinations, i.e., LukS-PV + LukF-PV (PVL), LukS-PV + $\mathrm{HlgB}, \mathrm{HlgA}+\mathrm{H} \operatorname{lgB}$, were not distinguishable. For these leucotoxins, a maximal IS of 12 was reached by injecting $3000 \mathrm{ng}$ dose of proteins constituting pairs, but only at $48 \mathrm{~h}$ after the injection. At the clinical level, these pairs were responsible for marked haemorrhage in the vitreous after injection of this dose. Secretions, oedema and blepharitis were significantly less pronounced than those obtained with the same doses of HlgA + LukF-PV and appeared later. These observations made the leucotoxin pair $\mathrm{HlgA}+$ LukF-PV significantly more effective than the three others listed earlier $(p<0.01)$. As an example, physiological solution containing $3000 \mathrm{ng}$ each of LukS-PV + LukF-PV induced a strong inflammatory reaction (Fig. 1B; IS $=10$ ) $24 \mathrm{~h}$ after injection, as compared with a normal eye (Fig. $1 \mathrm{~A}$; IS = 3). At this 


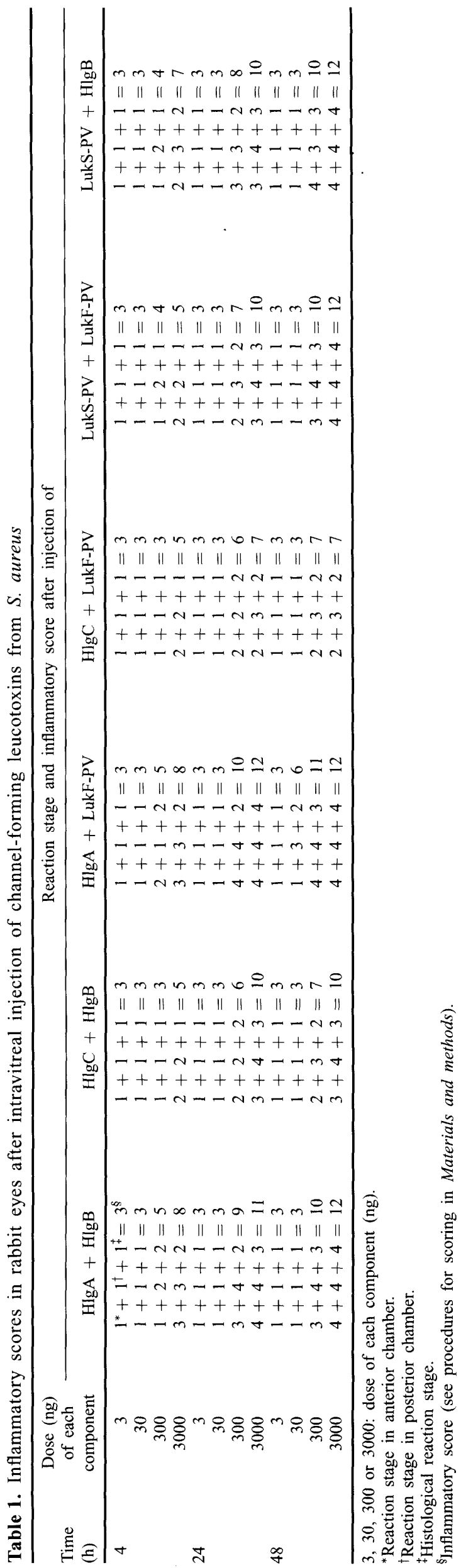



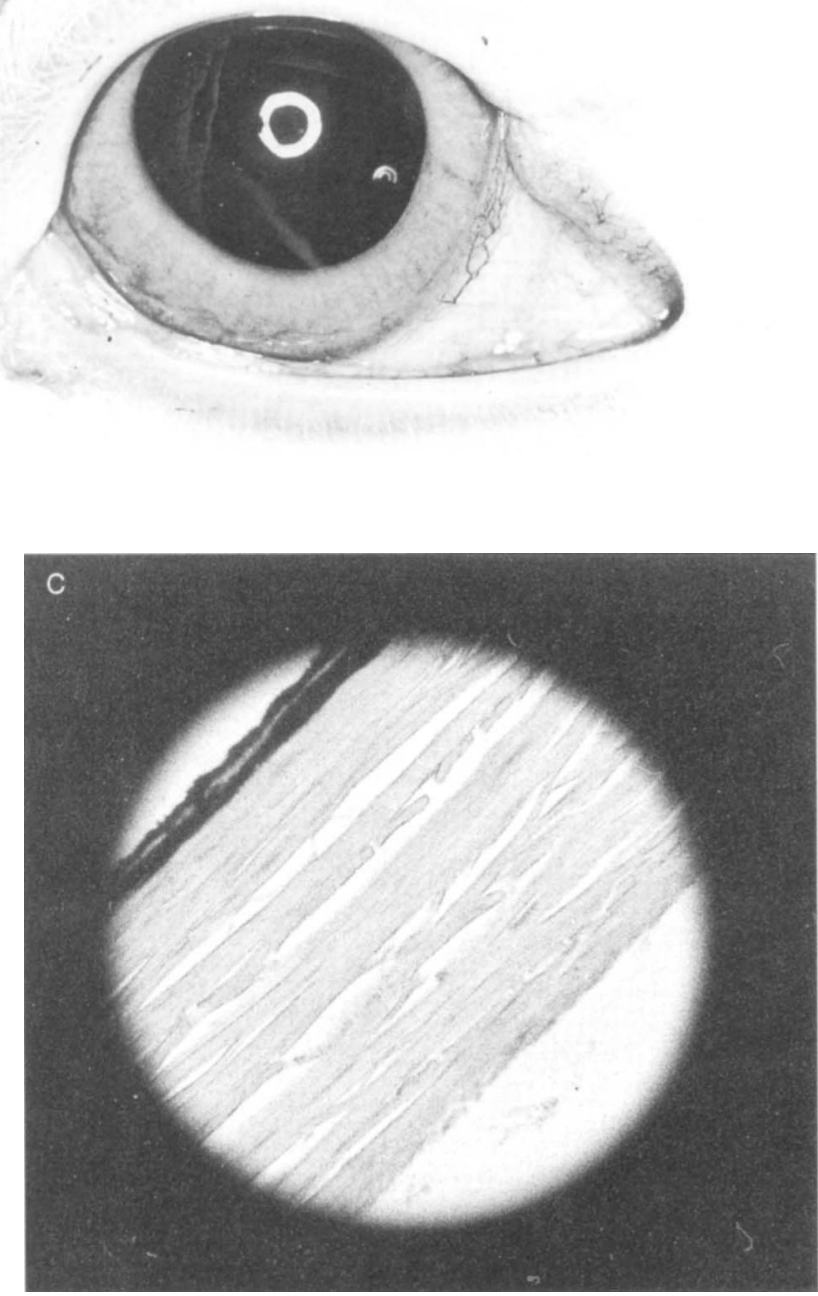
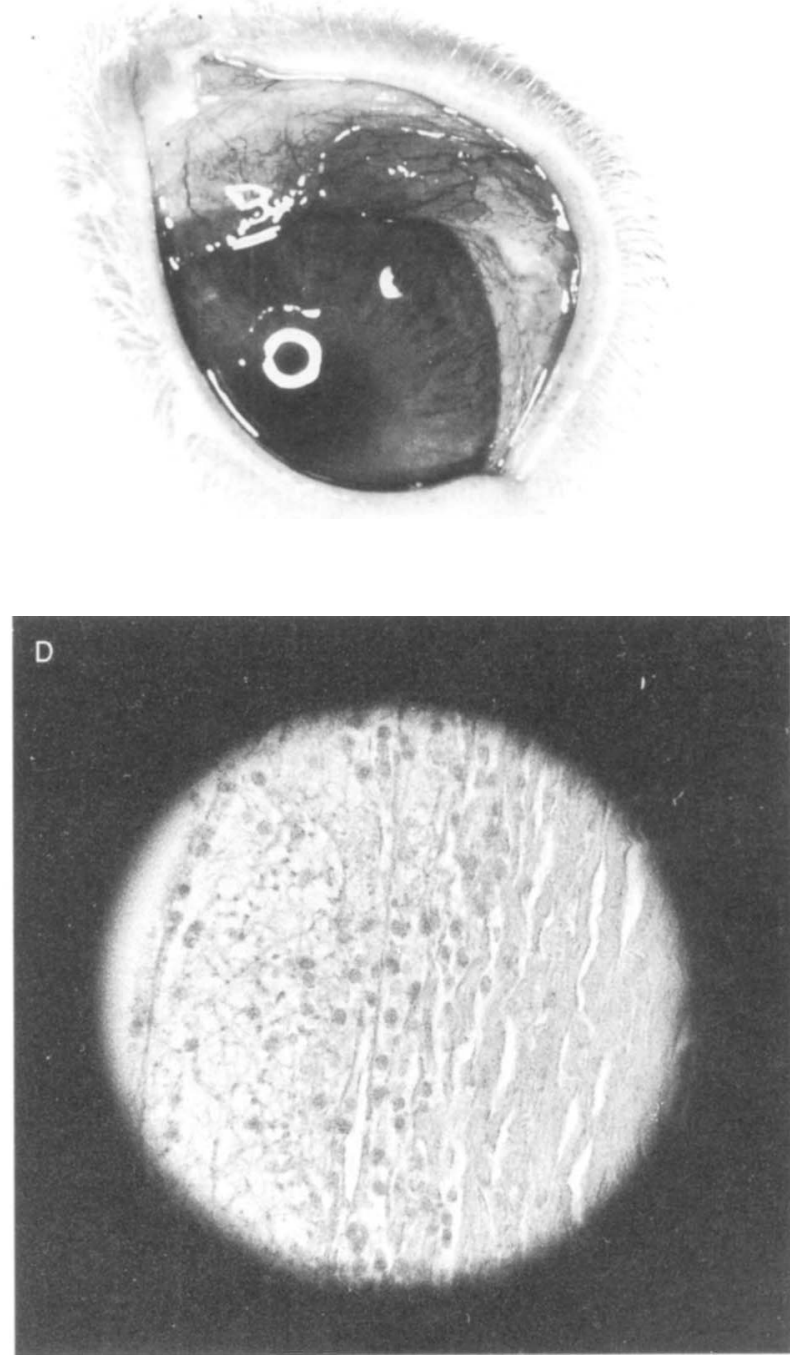

Fig. 1. Inflammatory reaction induced $24 \mathrm{~h}$ after intravitreal injection of $50 \mu \mathrm{l}$ of physiological and apyrogenic medium alone $(\mathbf{A}, \mathbf{C})$ or of $50 \mu 1$ of this medium containing an equimolar dose of $3000 \mathrm{ng}$ of PVL (B, D). The rabbit eye inoculated with PVL (B) exhibits oedema, blepharitis, total conjunctival hyperaemia, chemosis and haze in the anterior chamber. The histological sections of the normal rabbit eye show the sclera with no infiltrated cells (C), whereas for the PVL-injected eye, the width of the sclera increased (D), the retina did not appear to be homogeneously margined, and numerous neutrophils infiltrated tissues.

time, oedema, blepharitis, total conjunctival hyperaemia, chemosis and haze in the anterior chamber were already developed in the PVL-injected eye and were directly observable. Although histological section of the normal rabbit eye showed the sclera with no infiltrated cells (Fig. 1C), the PVL-injected eye revealed that the width of sclera increased, whereas the retina did not appear homogeneously margined, but numerous neutrophils had infiltrated the tissues (Fig. 1D).

For the last two leucotoxin pairs containing $\mathrm{HlgC}$ $\mathrm{HlgC}+\mathrm{HlgB}$ and $\mathrm{HlgC}+\mathrm{LukF}-\mathrm{PV}$ - significant secretion from the eye was never induced. Further- more, no significant necrosis of the tissues was evidenced and erythrocytes were not observed in the vitreous, whatever the dose tested and the time of observation after injection.

In other experiments, $300 \mathrm{ng}$ of either LukS-PV + LukF-PV or HlgA + LukF-PV were instilled on the conjunctiva or injected under the conjunctiva of rabbits' eyes, and clinical observations were made 4 , 24 and $48 \mathrm{~h}$ after injection. Instillation of these two pairs on the eye did not produce any detectable effect, but when injected under the conjunctiva they induced clinically observable stage 2 reactions in the anterior chamber at 4 and $24 \mathrm{~h}$. However, these reactions 
disappeared within $48 \mathrm{~h}$. In the posterior chamber, stage 2 lesions were observed only with injection of the pair HlgA + LukF-PV and not with PVL. These lesions appeared at $4 \mathrm{~h}$, and decreased to stage 1 at $24 \mathrm{~h}$. Channel-forming leucotoxins were much less damaging for the rabbit eye when instilled on the conjunctiva or injected under it, than when injected into the posterior chamber of the eye.

\section{Relationships between clinical and histological observations}

During the experiments, the inability to observe the optic nerve (stage 4 in the posterior chamber) was always associated with complete retinal necrosis (stage 4 at histological examination). The observation of a hypopyon in the anterior chamber (stage 4) always corresponded to the presence of fibrin on histopathological examination and always occurred $48 \mathrm{~h}$ after injection of $3000 \mathrm{ng}$ each of HlgA + LukF-PV and $\mathrm{H} \lg \mathrm{A}+\mathrm{HlgB}$.

The dose of $3000 \mathrm{ng}$ each of HlgA + LukF-PV in the vitreous induced ulceration of the cornea within $48 \mathrm{~h}$. Histological data confirmed the latter clinical feature by the presence of polymorphonuclear cell infiltrates in the corneal stroma (stage 4), and by the adhesion of the same cells to the corneal endothelium. This adhesion process had already begun $24 \mathrm{~h}$ after the injection. However, the state of the corneal endothelium could not be assessed because of damage to the tissue by formaldehyde.

\section{$N$-acetyl- $\beta$-D glucosaminidase}

$\mathrm{N}$-Acetyl- $\beta$-D glucosaminidase activity in rabbit eye - lysates was detectable $24 \mathrm{~h}$ after leucotoxin injection (Fig. 2). Results were expressed as $\mathrm{OD}_{405 \mathrm{~nm}}$ units because rabbit enzyme was not available. However, under experimental conditions, $1 \mathrm{OD}_{405 \mathrm{~nm}}$ unit corresponded to $6 \times 10^{-6} \mathrm{U}$ of human placental $\mathrm{N}$-acetyl $\beta$ $\mathrm{D}$ glucosaminidase assuming that one unit hydrolyses $1 \mu$ mole of the substrate in $1 \mathrm{~min}$ at $25^{\circ} \mathrm{C}$. A dose of $30 \mathrm{ng}$ each of $\mathrm{HlgA}+\mathrm{LukF}-\mathrm{PV}$ induced enzyme activity at levels of $0.75 \mathrm{SD} 0.08$ (arbitrary units) within $48 \mathrm{~h}$ and of $1.2 \mathrm{SD} 0.1$ within $72 \mathrm{~h}$. For all leucotoxins, only the equimolar doses of 300 and $3000 \mathrm{ng}$ induced significant amounts of enzyme within 24,48 or $72 \mathrm{~h}$ after injection. Time- and dosedependent reactions were also observed. Enzymic activities (48 and $72 \mathrm{~h}$ ) obtained with the combination HlgA + LukF-PV were significantly different $(\mathrm{p}<$ 0.01) from those found with pairs containing $\mathrm{HlgC}$. Potential of leucotoxins were in accordance with those determined by clinical and biological observations. However, if equimolar $300 \mathrm{ng}$ doses showed a continuous increase, it seemed that a plateau was reached about $48 \mathrm{~h}$ after injections.

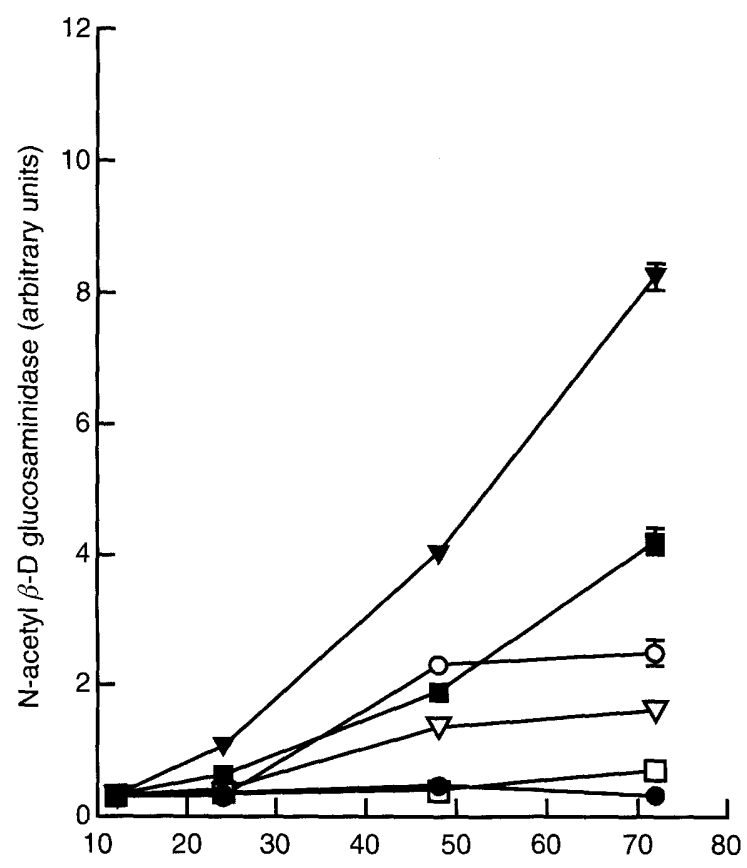

b

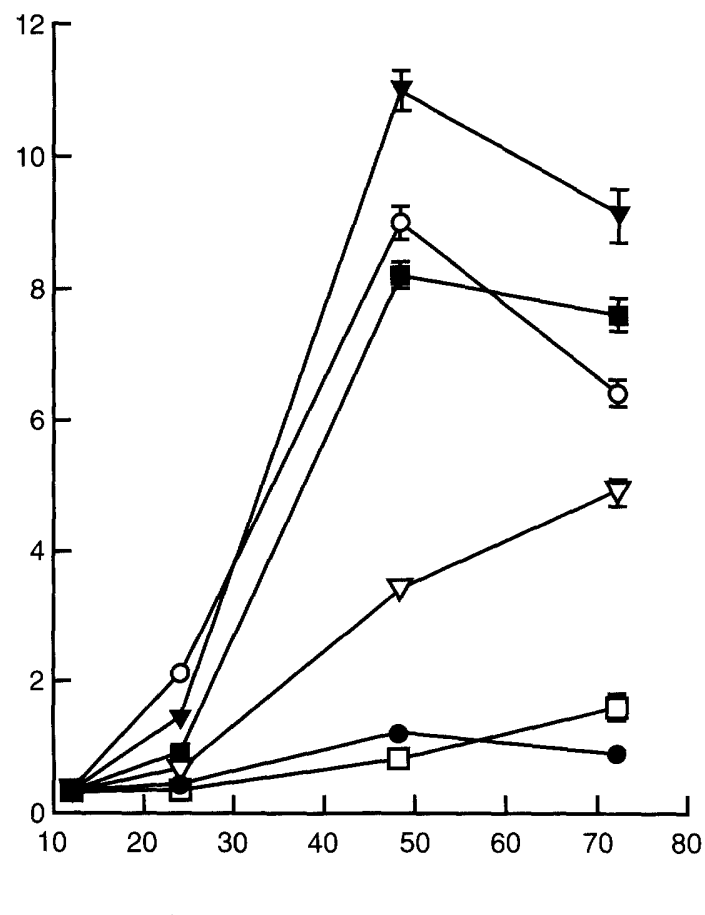

Fig. 2. N-Acetyl- $\beta$-D glucosaminidase activities (and SD as bar lines when no overlapping symbols) contained in $50 \mu 1$ of the four series of rabbit vitreous samples according to the time $(12,24,48$ or $72 \mathrm{~h})$ following the injection of $\mathrm{HlgA}+\mathrm{LukF}-\mathrm{PV}(\boldsymbol{\nabla}), \mathrm{HlgA}+\mathrm{HlgB}(\mathrm{O}), \mathrm{HlgC}+\mathrm{LukF}-\mathrm{PV}(\square), \mathrm{HlgC}+\mathrm{HlgB}(\mathbf{O}), \operatorname{LukS}-\mathrm{PV}+\mathrm{LukF}-\mathrm{PV}$ (口) and LukS-PV + HlgB $(\nabla)$. Panel a: $300 \mathrm{ng}$ of each protein; b: $3000 \mathrm{ng}$ of each protein. One arbitrary unit $\left(\mathrm{OD}_{405 \mathrm{~nm}}\right)$ corresponds to $6 \times 10^{-6} \mathrm{U}$ of the human placental enzyme. 


\section{Discussion}

Staphylococcal Panton-Valentine leucocidin and $\gamma$ haemolysin have been described recently [24] as members of a new family of bi-component exotoxins. Although most clinical $S$. aureus strains produce $\gamma$-haemolysin, only $2 \%$ of them also produce PVL. The latter strains are strongly associated with primary necrotising cutaneous infections in man, particularly with furuncles. The two toxins were reported to have distinct genetic locations and biological activities in vitro [3]. The simultaneous expression of PVL and $\gamma-$ haemolysin by $S$. aureus strains such as ATCC 49775 would generate six combinations of a type S component with a type $F$ component, which have been reported to have biological activity on human and rabbit PMNLs.

All channel-forming leucotoxins had strong inflammatory potential if injected in the vitreous of rabbit, thus mimicking the clinical signs of infectious endophthalmitis. The synergic effect of class $S$ and class $F$ components was observed once more and it was confirmed that each of the components alone had no damaging activity on the rabbit eye. The observed biological activities of leucotoxins were assumed to originate from the vitreous space as the two most potent pairs, when instilled on the conjunctiva or injected under this tissue, did not induce any significant effect. The same doses of the same toxins injected in the vitreous (e.g., $300 \mathrm{ng}$ each of $\mathrm{HlgA}+\mathrm{HlgB}$ or LukS-PV + LukF-PV led to maximal inflammatory effects within $48 \mathrm{~h}$. During experiments, it was observed that injection of toxins such as $\mathrm{Hlg} \mathrm{A}+\mathrm{HlgB}$ or $\mathrm{HlgA}+\mathrm{LukF}-\mathrm{PV}$ into the vitreous space were rapidly responsible for ulceration of the retina with significant cell recruitment. Therefore, cells sensitive to leucotoxins seem to exist within the vitreous, may be as the small number of macrophages normally present on the surface of the retina. It has been reported that platelet-activating factor may participate in the breakdown of the blood-retinal barrier [29]. Therefore, inflammatory cells sensitive to the leucotoxins remain to be characterised.

$\mathrm{HlgA}+$ LukF-PV was observed to be the most efficient leucotoxin pair because only $30 \mathrm{ng}$ of each component induced a significant biological effect within $48 \mathrm{~h}$. PVL-encloding genes are encountered in only $2 \%$ of clinical $S$. aureus strains, and are stable in these strains despite the constant presence of related genes (those encoding $\gamma$-haemolysin). However, PVL was reported earlier as the most dermonecrotising leucotoxin for rabbit skin. The latter biological activity may illustrate the benefit for such strains of maintaining expression of the two relevant loci. Such observations may bring into question the specificity of each leucotoxin in relation to certain inflammatory cells. Glucosaminidase assays revealed a delay between the presence of inflammatory cells observed by histology and the presence of a detectable enzymic activity. It was more likely associated with the beginning of tissue necrosis (stage 3 of histological examination). Therefore, infiltrated PMNLs would be activated further for the production of inflammatory mediators. As the different pairs induced various inflammatory reactions, it was not credible to parallel the glucosaminidase activity with the number of cells infiltrating the rabbit vitreous. Up to now, $\mathrm{HlgC}$ appears to be the least effective of the class $\mathrm{S}$ components tested, as none of the pairs that included this protein led to dramatic cytolytic levels or large inflammatory events. The simultaneous expression of $h l g \mathrm{~A}$ and $l u k F-P V$ genes in vivo by $S$. aureus strains remains to be demonstrated.

If such toxins are produced, they should account significantly for the pathogenicity of $S$. aureus infections. However, the role of channel-forming leucotoxins in the pathogenicity of bacteria should be assessed in conjunction with other virulence factors frequently encountered in $S$. aureus strains, such as $\alpha$-toxin. $\alpha$-Toxin had been described as a major virulence factor in staphylococcal keratitis [30]. It appears from this work that some leucotoxins injected under the conjunctiva led to moderate reactions of the anterior posterior chambers, indicating that both $\alpha$ toxin and leucotoxins may play roles in clinical manifestations of superficial eye infections. Moreover, recent work [31] showed that agr-defective (accessory gene regulator) strains had dramatically decreased pathogenicity in the rabbit eye.

Finally, the efficiency of a channel-forming leucotoxin was quite low if the class $\mathrm{S}$ component was HlgC. The nature of the class $\mathrm{F}$ component may also contribute to the efficacy of the leucotoxin, as the association of one of the two class $\mathrm{F}$ components (LukF-PV or HlgB) with HlgA induced lesions differing significantly from each other.

Host response to leucotoxins seemed to increase in progressive steps. These steps depended on the dose and on the efficiency of each combination. Assuming that all these six pairs probably have a similar catabolic turnover in this animal model (because they share $60-75 \%$ homology [3], the different effects of leucotoxins might be explained also by the relative affinity of the components, the specific kinetics of binding of class $\mathrm{S}$ components to cell ligands, or by the number of specific binding sites at the surface of target cells, depending on the toxin.

We thank Mrs J. Bornier for skilful technical assistance in the preparation of histological sections and $\mathrm{Mr}$ F. Stoeckler for photographs of the rabbit eyes. We thank G. Green for English reading. This work was supported by the Institut de Bactériologie de la Faculté de Médecine de Strasbourg. 


\section{References}

1. Woodin AM. The staphylococcal leukocidin. In: Cohen JO (ed) The staphylococci. New York, Wiley Interscience. 1972: 281-289.

2. Woodin AM. Purification of the two components of leucocidin from Staphylococcus aureus. Biochem J 1960; 75: $158-165$

3. Prévost G, Cribier B, Couppié et al. Panton-Valentine leucocidin and gamma-hemolysin from Staphylococcus aureus ATCC 49775 are encoded by distinct genetic loci and have different biological activities. Infect Immun 1995; 63: 4121-4129.

4. Supersac G, Prévost G, Piémont Y. Sequencing of leucocidin $\mathrm{R}$ from Staphylococcus aureus P83 suggests that staphylococcal leucocidins and gamma-hemolysin are members of a single, two-component family of toxins. Infect Immun 1993; 61: $580-587$.

5. Panton PN, Valentine FCO. Staphylococcal toxin. Lancet 1932; 1: 506-508.

6. Finck-Barbançon V, Prévost G, Piémont Y. Improved purification of leukocidin from Staphylococcus aureus and toxin distribution among hospital strains. Res Microbiol 1991; 142: $75-85$.

7. Llewellyn-Smith M, Price SA. Staphylococcus $\gamma$-haemolysin. $J$ Pathol Bacteriol 1938; 47: 379-393.

8. Guyonnet F, Plommet M. Hémolysine gamma de Staphylococcus aureus: purification et propriétés. [Gamma hemolysin of Staphylococcus aureus: purification and properties.] Ann Inst Pasteur 1970; 118: 19-33.

9. Soboll H, Ito A, Schaeg W, Blobel H. [Leukocidin from staphylococci of different origin.] Zentralbl Bakteriol Orig $A$ 1973; 224: 184-193.

10. Taylor AG, Bernheimer AW. Further characterization of staphylococcal gamma-hemolysin. Infect Immun 1974; 10: 54-59.

11. Cooney I, Kienle Z, Foster TJ, O'Toole PW. The gammahemolysin locus of Staphylococcus aureus comprises three linked genes, two of which are identical to the genes for the $\mathrm{F}$ and $\mathrm{S}$ components of leukocidin. Infect Immun 1993; 61: $768-771$.

12. Kamio Y, Rahman A, Nariya H, Ozawa T, Izaki K. The two staphyloccocal bi-component toxins, leukocidin and gammahemolysin, share one component in common. FEBS Lett 1993; 321: 15-18.

13. Finck-Barbançon V, Duportail G, Meunier O, Colin DA. Pore formation by a two-component leukocidin from Staphylococcus aureus within the membrane of human polymorphonuclear leukocytes. Biochim Biophys Acta 1993; 1182: $275-282$.

14. Colin DA, Mazurier I, Sire S, Finck-Barbançon V. Interaction of the two components of leukocidin from Staphylococcus aureus with human polymorphonuclear leukocyte membranes: sequential binding and subsequent activation. Infect Immun 1994; 62: 3184-3188.

15. Meunier O, Falkenrodt A, Monteil H, Colin DA. Application of flow cytometry in toxinology: pathophysiology of human polymorphonuclear leukocytes damaged by a pore-forming toxin from Staphylococcus aureus. Cytometry 1995; 21: $241-247$.
16. Gladstone GP, van Heyningen WF. Staphylococcal leucocidins. Br J Exp Pathol 1957; 38: 123-137.

17. Couppié P, Cribier B, Prévost G, Grosshans E, Piémont Y. Leucocidin from Staphylococcus aureus and cutaneous infections: an epidemiologic study. Arch Dermatol 1994; 130: $1208-1209$.

18. Cribier B, Prévost G, Couppié P, Finck-Barbançon V, Grosshans E, Piémont Y. Staphylococcus aureus leukocidin: a new virulence factor in cutaneous infections? An epidemiological and experimental study. Dermatology 1992; 185: $175-180$.

19. Ward PD, Turner WH. Identification of staphylococcal Panton-Valentine leukocidin as a potent dermonecrotic toxin. Infect Immun 1980; 28: 393-397.

20. Prévost G, Couppié P, Prévost $P$ et al. Epidemiological data on Staphylococcus aureus strains producing synergohymenotropic toxins. J Med Microbiol 1995: 42: 237-245.

21. Hensler T, König B, Prévost G, Piémont Y, Köller M, König W. Leukotriene B4-generation and DNA fragmentation induced by leukocidin from Staphylococcus aureus: the protective role of granulocyte-macrophage colony stimulating factor (GM-CSF) and G-CSF for human neutrophils. Infect Immun 1994; 62: 2529-2535.

22. König B, Köller M, Prévost G. et al. Activation of human effector cells by different bacterial toxins (leukocidin, alveolysin, erythrogenic toxin $\mathrm{A}$ ), generation of interleukin8. Infect Immun 1994; 62: 4831-4837.

23. Hensler T, Köller M, Prévost G, Piémont Y, König W. GTPbinding proteins are involved in the modulated activity of human neutrophils treated with the Panton-Valentine leukocidin from Staphylococcus aureus. Infect Immun 1994; 62: 5281-5289.

24. König B, Prévost G, Piémont Y, König W. Effect of Staphylococcus aureus leucocidins inflammatory mediator release from human granulocytes. $J$ Infect Dis 1995; 171: $607-613$.

25. Forster RK, Abbott RL, Gellender H. Management of endophthalmitis. Ophthalmology 1980; 87: 313--319.

26. Mao LK, Flynn HW, Miller D, Plugfelder SC. Endophthalmitis caused by Staphylococcus aureus. Am J Ophthalmol 1993; 116: $584-589$.

27. Johnson MK, Hobden JA, Hagenah M, O'Calleghan RJ, Hill JM, Chen S. The role of pneumolysin in ocular infections with Streptococcus pneumoniae. Curr Eye Res 1990; 9: 1107-1114.

28. Nussenblatt RB, Palestine AG, Chan CC, Roberge F. Standardization of vitreal inflammatory activity in intermediate and posterior uveitis. Ophthalmology 1985; 92: 467-471.

29. Smith D, Lee EK, Saloupis P, Davis JK, Hatchell DL. Role of neutrophils in breakdown of the blood-retinal barrier following intravitreal injection of platelet-activating factor. Exp Eye Res 1994; 59: 425-432.

30. Callegan MC, Engel LS, Hill JM, O'Callaghan RJ. Corneal virulence of Staphylococcus aureus: roles of alpha-toxin and protein $\mathrm{A}$ in pathogenesis. Infect Immun 1994; 62: 2478-2482.

31. Booth MC, Atkuri RV, Nanda SK, Iandolo JJ, Gilmore MS. Accessory gene regulator controls Staphylococcus aureus virulence in endophthalmitis. Invest Ophthalmol Vis Sci 1995; 36: $1828-1836$. 